\title{
Research on the Effect of Fly Ash Content on the Tensile Properties of PVA -ECC
}

\author{
Wan Li \\ College of Engineering \\ China University of Geosciences \\ Wuhan, Hubei, 430074, China \\ E-mail: 1061669626@qq.com. \\ Xiaoyong Zhou* \\ College of Engineering \\ China University of Geosciences \\ Wuhan, Hubei, 430074, China \\ E-mail: xyzts@163.com.
}

\author{
$\mathrm{Na} \mathrm{Li}$ \\ Department of Urban Construction \\ Wen Hua College \\ Wuhan, Hubei, 430074, China \\ E-mail: xyzlina@qq.com.
}

\begin{abstract}
The stress-strain relationship and tensile resistance parameters of polyvinyl alcohol fiber reinforced cementitious composite(PVA-ECC) are studied and analyzed experimentally by uniaxial tensile test. The specimens are $200 \mathrm{~mm} \times 50 \mathrm{~mm} \times 20 \mathrm{~mm}$ with different fly ash content. The test is carried out by using displacement controlled test installation and complete stress-strain curves are obtained. The results show that with the increase of fly ash content, the concrete strength and average crack spacing show a trend of decrease after the first increase, the tensile strain increases gradually and the maximum value is $6.23 \%$, the average crack width decreases gradually. In this experiment the best fly ash content is $70 \%$. If the drop of compressive strength of ECC is permit, increasing fly ash content appropriately will help to further improve the toughness and ductility of PVA fiber reinforced cementitious composite.
\end{abstract}

Keywords-fiber reinforced cementitious composite;tensile properties; fly ash content; crack width

\section{INTRODUCTION}

In the traditional reinforced concrete structure, cracks are affecting the primary factor in the quality and durability of concrete structure, due to the cracks will cause steel corrosion, affect the structure durability and service life. How to effectively control the generation and expansion of cracks in concrete is the key to solve the problems of durability of concrete structure. In order to overcome the brittleness of concrete material and the strain softening characteristic, a large number of researchers began by means of microstructure and mesomechanics to study with strain hardening characteristics of cementitious composite. Engineering cementitious composite(ECC )is the more successful one of cementitious composite, it is designed based on mesomechanics and has strain hardening properties[12].The basic design idea of the material was most early proposed with the basic principles of mesomechanics and fracture mechanics by professor Victor C.Li of the University of Michigan and professor Leung of the University of Massachusetts[3]. Its specific definition is: use short fiber reinforced, and the fiber content does not exceed $2.5 \%$ of the composite material volume, hardened composite materials should have significant strain - hardening characteristics, under direct tensile load can produce a plurality of fine cracks, and ultimate tensile strain can be stable over 3\%[4]. The main difference between ECC and traditional fiber reinforced cementitious composite is that the components of ECC is designed based on mesomechanics, and the mechanical properties of design is the core of the material ratio design. In addition, the strain hardening characteristics of ECC is refers to the performance that the material in uniaxial tension, before to achieve ultimate tensile strain, the bearing capacity is not reduced, and the strain continues to increase.

Because the fly ash has micro aggregate effect, active effect and morphological effects, its application in the cement concrete material has been more than half a century. Fly ash can improve various properties of cement concrete, such as the liquidity of the fresh concrete mixture and the durability of concrete required in the process of using[5].Fly ash, as one of the admixture of PVA-ECC materials, can reduce the dosage of cement, achieve the goal of reducing production costs, and make PVA-ECC to become environmentally friendly material and conducive to the sustainable development. But for what content of fly ash, the PVA- ECC optimal performance is obtained, domestic and foreign research on this aspect has still not been agreed.

In $2005 \mathrm{~S}$. X. Wang et al.[6] made tensile test of PVAECC with the FA/C (fly ash and cement ratio) between 0 to 1.5 , the results showed that PVA-ECC strain capacity increased with the increase of $\mathrm{FA} / \mathrm{C}$, and it also showed that the addition of fly ash is conducive to the pseudo strain hardening of PVA-ECC. In 2007, Shuxin Wang and Victor C. Li[7] studied the mechanical properties of PVAECC with large volume content fly ash $(\mathrm{FA} / \mathrm{C}=0.1 \sim$ $1.5)$, they found that with the increase of the content of fly ash, the tensile strain of ECC increased gradually, but the influence rule of cracking strength and ultimate tensile 
strength was not obvious. Tsinghua University in 2008, ChengXu Gong et al.[8] carried out the uniaxial direct tensile test of PVA-ECC with different water cement ratio $(0.45,0.45)$ and fly ash content $(0,0.2,0.4)$, the test results showed that: when the water cement ratio was 0.5 and $40 \%$ dosage of fly ash, the ultimate tensile strain reached a maximum value of $1.7 \%$, while under a certain water-binder ratio, the addition of fly ash contributed to the decrease of the crack width. In 2009 Yingzi Yang et al.[9]studied the bending properties, compressive flexural strength and tensile cracking performance of PVA-ECC with different fly ash content $(50 \%, 60 \%, 70 \%, 80 \%)$, the results showed that with the increase of fly ash content, the initial cracking load of PVA-ECC was decreased, and the compressive flexural strength was gradually reduced, While the deflection of ECC beam gradually improved and the average crack width of ECC became small.

At present, there is few research on the effect of fly ash on the bonding interface between fiber and matrix, the tensile properties and toughness of PVA-ECC. In this paper, we study under the condition of a certain ratio of material, change the content of fly ash, and through direct tensile test, the tensile resistance parameters of PVA-ECC such as tensile strength, toughness, crack width and spacing are studied with different content of fly ash. And then we can determine the optimal content of fly ash, prepare the fiber reinforced cementitious composite with ultra high toughness and excellent crack controlability, and provide the necessary reference for the engineering application of ECC.

\section{THE PVA-ECC DIRECT TENSILE TEST}

\section{A. Test Material}

The PVA fiber in our test is made in Japan, and its single length is 12 millimeter(its performance parameters are shown in TABLE I). The cement is $\mathrm{P} \cdot \mathrm{O} 42.5$ ordinary portland cement, the fly ash is secondary, and the water reducing agent is a high performance polycarboxylate water reducing agent, the fine sand is standard sand with particle size less than 160 microns and the mixing water use drinking tap water. In addition to the fiber, all other raw materials are produced in domestic. The material ratio in the test is: the water cement ratio is 0.65 , and the sand binder ratio is 0.36 , using 6 groups of different fly ash content $(50 \%, 55 \%, 60 \%, 65 \%, 70 \%, 75 \%$, both for the substitution amount of cement), each group set of 3 specimens, and the fiber volume fraction is $2 \%$.

TABLE I. PROPERTIES OF PVA FIBER

\begin{tabular}{|c|c|c|c|c|c|}
\hline $\begin{array}{c}\text { Length } \\
(\mathbf{m m})\end{array}$ & $\begin{array}{c}\text { Diameter } \\
(\boldsymbol{\mu m})\end{array}$ & $\begin{array}{c}\text { Tensile } \\
\text { Strengt } \\
\mathbf{h}\end{array}$ & $\begin{array}{c}\text { Elongation } \\
(\mathbf{~ \% )}\end{array}$ & $\begin{array}{c}\text { Elasticity } \\
\text { Modulus } \\
(\mathbf{G P a})\end{array}$ & $\begin{array}{c}\text { Density } \\
(\mathbf{g} / \mathbf{c m 3})\end{array}$ \\
\hline 12 & 39 & 1620 & 7 & 43 & 1.3 \\
\hline
\end{tabular}

\section{B. Specimen Molding and Curing}

All of the mixing materials are complete in Model JJ 5 type mixer, the specific process is as follows:

Step1: Mix the cement, fly ash and fine sand after weighing, low-speed stir 2 minutes, then add water stir 2 to 4 minutes. Slowly add water reducing agent and continue to stir 3 to 5 minutes to get uniform flow matrix.

Step2: Low speed mix and manual slowly add fiber to ensure the fiber is uniformly and not appeared the cluster phenomenon, stir more 4 to 6 minutes after the fiber fully added.

Step3: All specimens use single-layer pouring with organic glass mold (as shown in Fig.1), the size of the mold is $200 \mathrm{~mm} \times 50 \mathrm{~mm} \times 20 \mathrm{~mm}$, and then specimens are on the vibration table vibrating about 1 minute.Maintenance and dismantle after 24 hours, and then put them into the standard curing room for water conservation to 7 days. The specimens are shown in Fig.2.

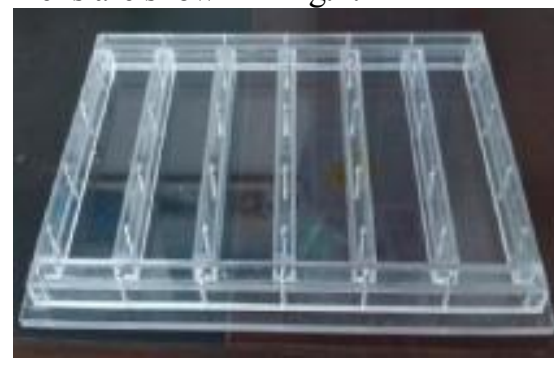

Figure 1. Specimen mold

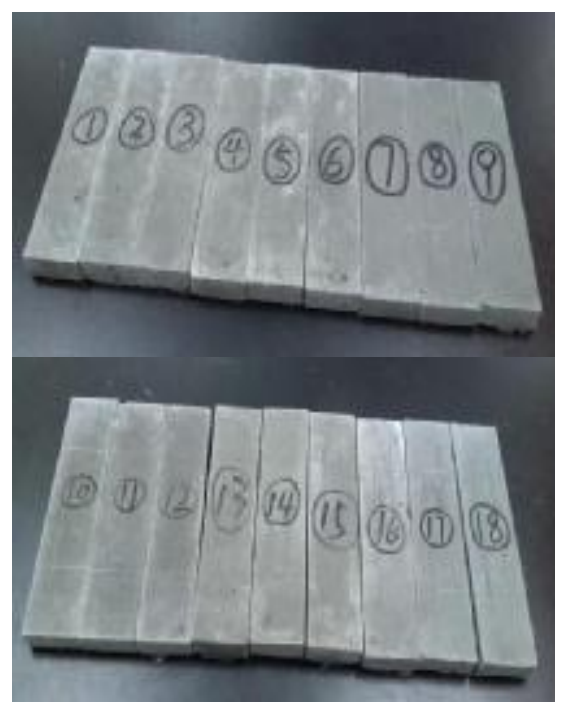

Figure 2. Specimens

\section{Direct Tensile Test}

Direct tensile test use America CMT5305 300kN type microcomputer control electronic universal testing machine. Before the installation of specimen, we should first confirm the testing machine upper and lower clamping fixture are in the same plane after clamping. Loading by using displacement control mode, the speed is $0.1 \mathrm{~mm} / \mathrm{min}$, and then remain constant throughout the test process. The test is finished until the specimen with a crack appeared on the localization extension. Test data including time, displacement, bearing capacity and the strain. Direct tensile test site photos as shown in Fig. 3. 


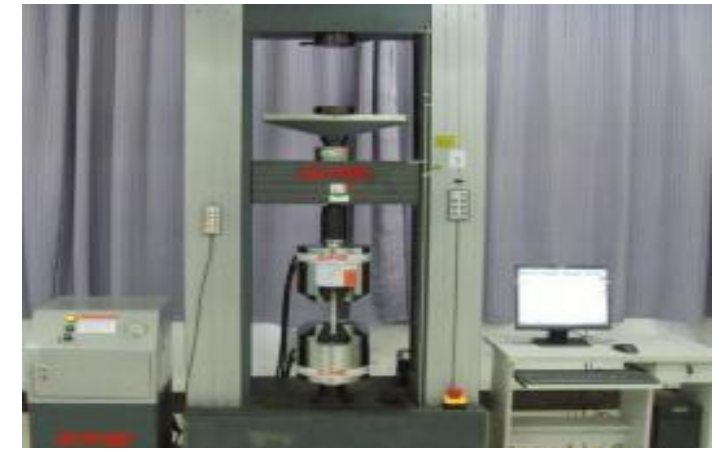

Figure 3. Photo of uniaxial tensile test on ECC

\section{TEST RESULTS AND ANALYSIS}

Produce more fine crack and equivalent strain hardening is the basic characteristics of PVA fiber reinforced cementitious composites. In the process of direct tension test, with the increase of load, the tensile deformation of the specimen only increases a little at the beginning. When the load reach cracking load, the initial crack is produced in the biggest defect of specimen. After the first crack appears, the load begin to decline. The load will increase again due to the bridging role of fiber during the process of crack development. The load continues to increase would make the tensile specimens produced second crack, so repeatedly, the specimen showed a substantially uniformly distributed multiple fine cracks[10]. The formation of the multiple micro cracks make the tensile deformation increase, the bridging stress of fiber between the crack is not enough to make the new cracks in the matrix, the cracks are in the saturated state. With the increase of load, there will be no new cracks, but the original width of crack growth, until a crack becomes primarily crack, the fiber will be pulled out or break, and make the specimen fracture damage eventually. The direct tensile stress-strain curves of each group are shown in Fig. 4.

As can be seen from Fig.4, all the content of fly ash have strain hardening and multiple cracking characteristics. The ultimate tensile strain is obviously improved compare with ordinary concrete, and the fly ash content has a certain effect on the material uniaxial tensile properties. But at the same amount of fly ash, the tensile performance of the specimen show large discreteness, and it means the uniformity of the composite material should be improved. At the same time also shows that the composite material has high requirement to the mixing and molding.

According to the measured curve can determine the relevant tensile performance parameters with different fly ash content (as shown in TABLE II).
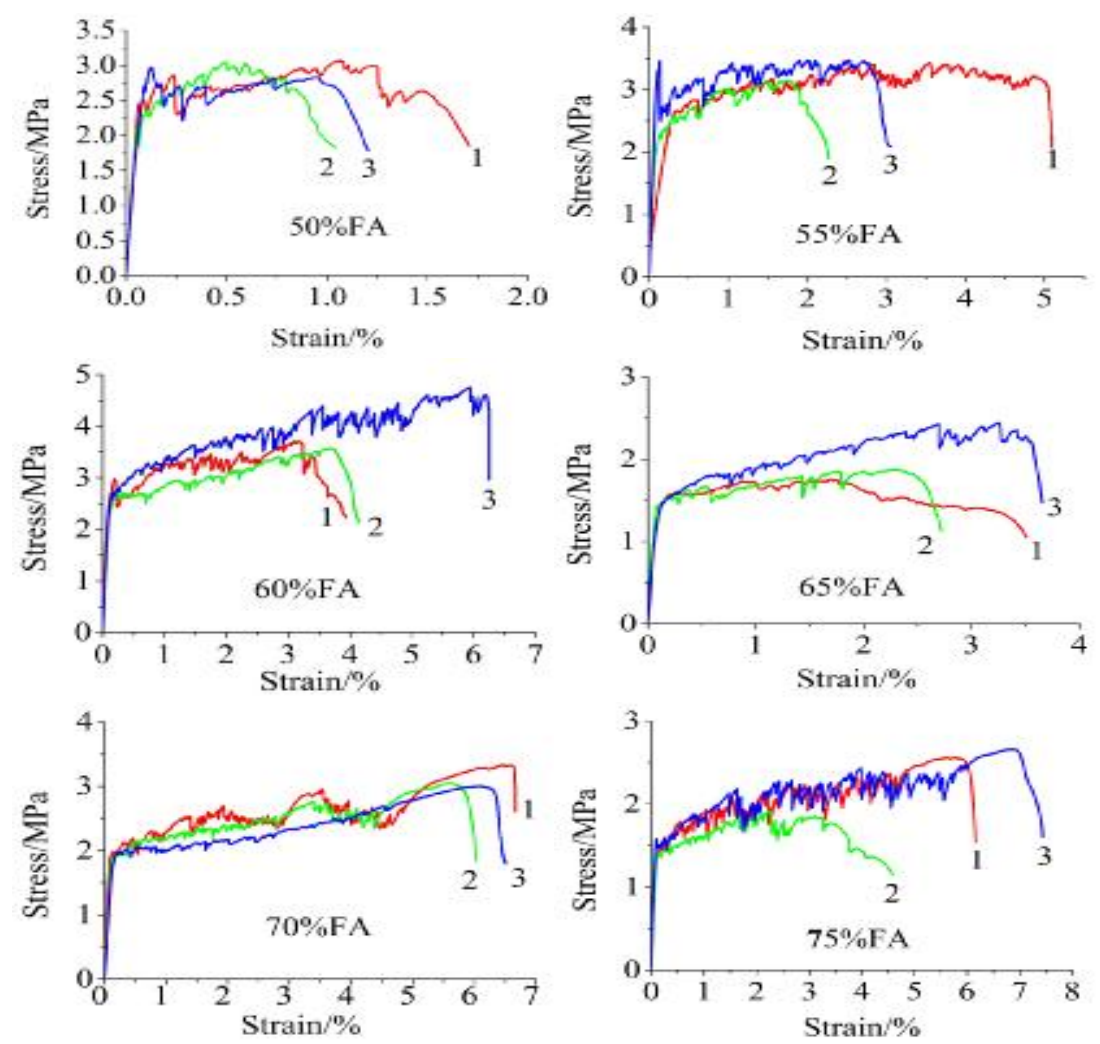

Figure 4. Stress-strain curves of uniaxial tensile test

TABLE II.

UNIAXIAL TENSILE TEST RESULT

\begin{tabular}{|c|c|c|c|c|c|c|c|}
\hline NO. & $\sigma_{\mathrm{C}}(\mathrm{MPa})$ & $\varepsilon_{\mathrm{C}}(\%)$ & $\sigma_{\mathrm{T}}(\mathrm{MPa})$ & $\varepsilon_{\mathrm{T}}(\%)$ & $\mathrm{Wa}(\mathrm{mm})$ & $\mathrm{Sa}(\mu \mathrm{m})$ & $\mathrm{E}_{\mathrm{S}}(\mathrm{MPa})$ \\
\hline $\mathbf{5 0 \%} \mathrm{FA}$ & $\mathbf{2 . 5 9}$ & $\mathbf{0 . 0 9}$ & $\mathbf{3 . 0 2}$ & $\mathbf{0 . 6 0}$ & $\mathbf{1 . 0 5}$ & $\mathbf{8 7}$ & $\mathbf{6 3 . 3 8}$ \\
\hline $\mathbf{5 5 \%}$ FA & $\mathbf{2 . 4 7}$ & $\mathbf{0 . 1 3}$ & $\mathbf{3 . 4 5}$ & $\mathbf{3 . 0 4}$ & $\mathbf{1 . 2 7}$ & $\mathbf{6 8}$ & $\mathbf{3 0 . 7 0}$ \\
\hline
\end{tabular}




\begin{tabular}{|l|l|l|l|l|l|l|l|}
\hline $60 \%$ FA & 2.85 & 0.19 & 3.64 & 3.38 & 1.4 & 45 & 34.91 \\
\hline $65 \%$ FA & 1.56 & 0.20 & 1.82 & 1.99 & 1.26 & 39 & 14.98 \\
\hline $70 \%$ FA & 1.95 & 0.18 & 3.13 & 6.06 & 1.18 & 26 & 19.94 \\
\hline $75 \%$ FA & 1.46 & 0.10 & 2.61 & 6.23 & 1.14 & 21 & 18.13 \\
\hline
\end{tabular}

Notes: $\sigma \mathrm{C}-$ Cracking strength; $\varepsilon \mathrm{C}-$ Cracking strain; $\sigma \mathrm{T} —$ Tensile strength; $\varepsilon \mathrm{T}-\mathrm{Tensile} \mathrm{strain}$;

Wa - Average crack width; Sa — Average crack spacing; ES—Strengthening phase slope.

\section{A. Effect of Fly Ash Content on the Properties of PVA- ECC}

By the results in TABLE II and Fig.5 show that, with the increase of fly ash content, the cracking strength and tensile strength of ECC shows a trend of decrease after the first increase, while the tensile strain increases gradually, and the maximum tensile strain can reach $6.23 \%$. When fly ash content increased from $50 \%$ to $60 \%$, the cracking strength and tensile strength reached the maximum value, respectively $2.85 \mathrm{MPa}$ and $3.64 \mathrm{MPa}$. When the fly ash content exceeds $60 \%$, the cracking strength and tensile strength began to decrease, while the tensile strain continues to increase. In the early age, because the fly ash does not participate in the hydration reaction, fly ash mixed in the cementitious composites and produced micro aggregate effect [11], namely the fly ash of glass beads have the effect of the "ball bearing lubrication", it improved the density of cementitious composites and reduced the internal porosity. With the increase of the content of fly ash, the matrix is more uniform and the structure of the differences between each section is relatively narrow, so the tensile strength and cracking strength showed a trend of increase first. As the continued increase of fly ash content, the cement content is reduced, thus reduce the hydration speed of composite materials, resulted in the weakening of matrix strength. It shows that there is a critical value of matrix strength with fly ash content, when more than the critical value, the fly ash micro aggregate effect is not obvious and the fly ash micro aggregate effect is not obvious. The best content fly ash for the matrix strength is $60 \%$ in this experiment.

The main characteristic parameters of the fiber matrix interface which are chemical bonding strength and friction bonding strength. Large amount of fly ash mixed in the material, the fly ash particles adhere on the fiber surface can avoid the direct contact of the fiber and matrix of hydration products, and also reduced the skiving of matrix of the fibers, make the chemical bonding properties of the fiber and matrix interface is weaken and each force section of matrix is easy to crack. So that more fiber stress at an earlier stage, fiber enhancement effect is improved, sliphardening effect reflected and tensile strain increases gradually.

With the increase of fly ash content, the crack strain of composite materials is within the scope of $0.1 \%$ $0.2 \%$, it shows that fly ash content does not have obvious effect on the early cracking strain of the composite material. It should be pointed out that, when fly ash is $65 \%$, the tensile strength and strain are low, this may be related to specimen did not stir well or eccentric loading appeared in the process of direct tension test, so it needs to remake composite materials tensile properties test with $65 \%$ content fly ash, in order to accurately determine tensile properties under this content .

Seen from TABLE II, when the fly ash content increased from $70 \%$ to $75 \%$, the tensile strength is decreased by $16.6 \%$ and the tensile strain increases $2.8 \%$. Compare with the tensile strength and tensile strain, the optimal content of fly ash is $70 \%$ in this experiment.
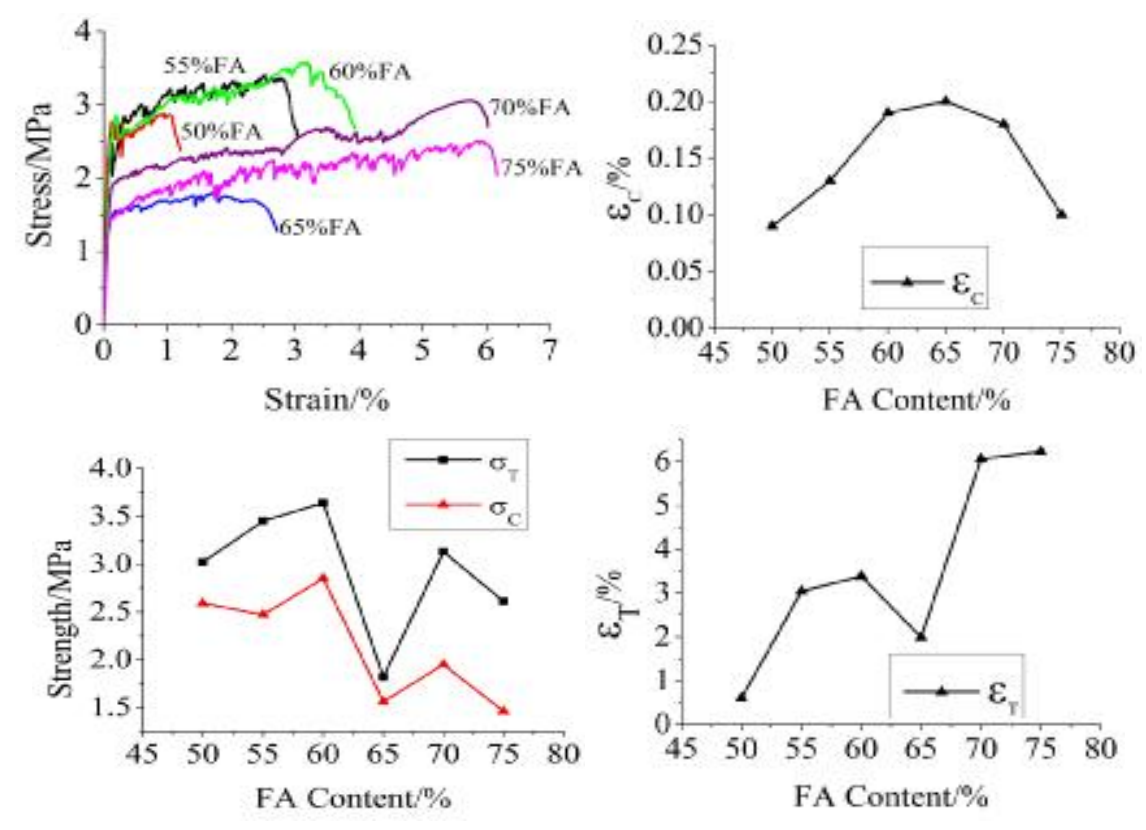

Figure 5. Effect of fly ash content on the properties of PVA-ECC 


\section{B. Effect of Fly Ash Content on Average Crack Width and Spacing of PVA-ECC}

By shown in Fig. 6, with the increase of fly ash content, the composite average crack width decreases. When the fly ash content is $75 \%$, the average crack width achieves the minimum 21 microns. While the average crack spacing is first increases then decreases, when the fly ash content is $60 \%$, the maximum average crack spacing is $1.4 \mathrm{~mm}$, then with the fly ash content continues to increase, the average crack spacing decreases gradually.

According to the above, when the amount of fly ash increases from $50 \%$ to $60 \%$, the matrix strength increases gradually, the bond strength between fiber and matrix is enhanced, which makes the fiber slip hardening effect is not obvious, reflected in the macro is less number of average crack and the crack spacing is larger. When the fly ash content exceeds $60 \%$, the matrix strength gradually weakened, the right amount of fly ash can coordinate the fiber interface bonding effect and sliding friction effect, make the time of the fiber transfer stress in the matrix prolonged, thus make crack cracking phenomenon is more sufficient, and crack spacing decreases and uniform, the average crack width also decreases.
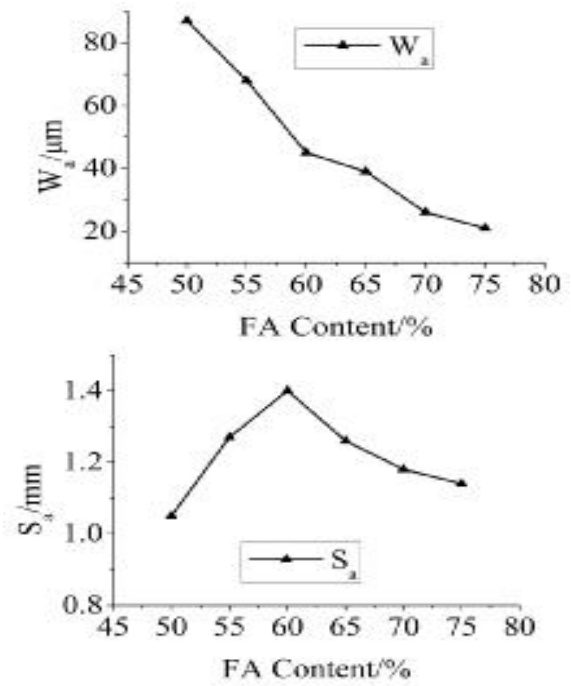

Figure 6. Effect of fly ash content on average crack width and spacing of PVA-ECC

\section{Effect of Fly Ash Content on Strengthening Phase Slope of PVA-ECC}

It can be seen from Fig. 7, with the increase of fly ash content, PVA cementitious composite reinforced phase slope decreases gradually. Stress-strain curve of the strengthening phase slope reflects the composite materials in the strain - hardening phase steady-state crack stability and uniformity. When the content of fly ash is small, the cement matrix strength is greater, the bond strength between fiber and matrix is also strong. In the process of direct tensile test, matrix cracking after fiber bridging effect is not obvious,slip hardening effect is abate, make the cementitious composite from cracking to damage process faster and uneven. In the macroscopic performance as a small number of cracks and average crack spacing is larger, the stress - strain curves has more fluctuation and strain hardening rate is larger. Along with the increase of fly ash content, the matrix strength gradually weakened, improve the bonding effect and sliding friction effect of the fiber matrix interface, the fiber transfer should extend force time in the matrix, enhanced slip hardening effect, so that the phenomenon of multiple cracking more fully, the steady cracking process of composite materials tend to be stable and uniform, crack spacing decreases gradually and evenly, the stress-strain curve is smooth, strain hardening rate is low.

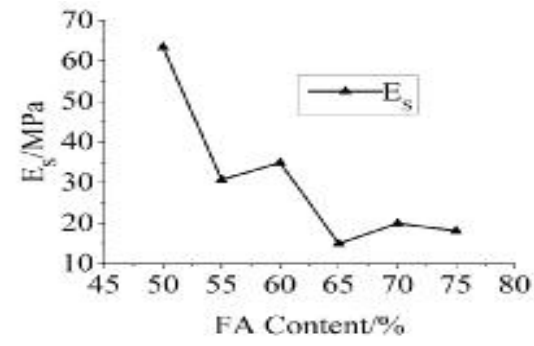

Figure 7. Effect of fly ash content on the strengthening phase slope of PVA-ECC

\section{Effect of Fly Ash Content on Micro Structure of PVA- ECC}

As shown in Fig.8, compare with different fly ash content of the fiber matrix interface morphology of SEM, when the content of fly ash is less than $60 \%$, fly ash and matrix combined with close, the micro aggregate effect of fly ash and the matrix strength increases, there is little fly ash break away from the matrix and fly ash particles adhere on the fiber surface is rarely, which makes the fiber and matrix higher bond strength, weak fiber toughening effect of fiber, more appear pull off type failure. With the increase of fly ash content, the matrix strength gradually weakened, the fly ash break away from the matrix and attached to the surface of fiber. It avoids direct contact with the fiber and the matrix of hydration products, but also reduce the matrix to the fiber scraping effect, and makes the fiber slip hardening effect enhancement, multiple cracking phenomenon of composite materials is stable and uniform, the tensile strain increases gradually, this fiber belongs to pull out the type of failure.

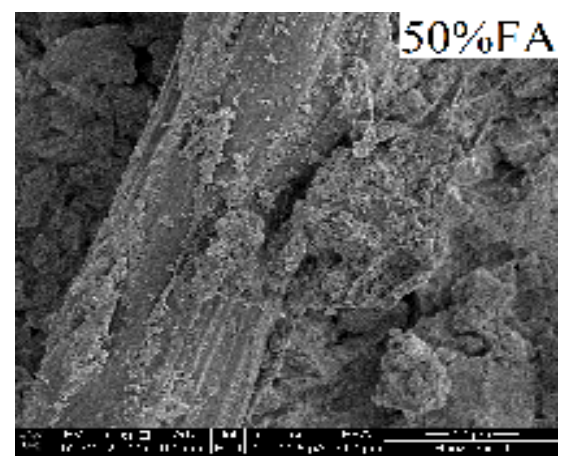




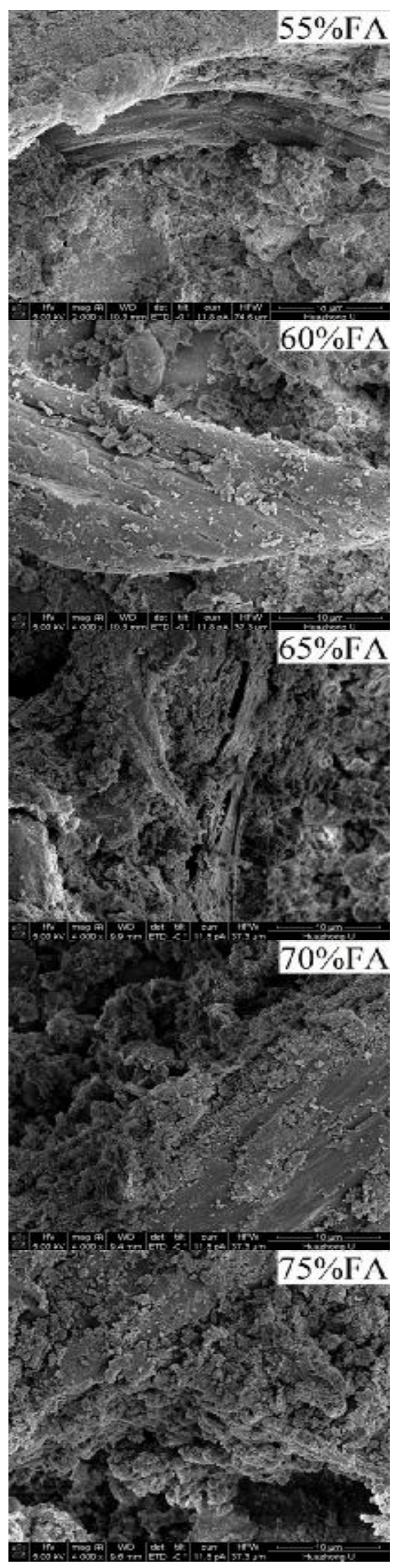

Figure 8. Effect of fly ash content on the SEM of PVA-ECC

\section{CONCLUSIONS}

Based on the direct tensile test, study the different fly ash content of stress-strain characteristics and related parameters of PVA fiber reinforced cementitious and composite .The experimental results showed that:

i) With the increase of fly ash content, matrix cracking strength, tensile strength and average crack spacing shows a trend of decrease after the first increase, tensile strain increases gradually, the maximum tensile strain can reach $6.23 \%$, the average crack width also gradually decreases, and minimum average crack width is 21 microns.

ii)According to the test results of 6 fly ash content in the experiment,compare with the tensile strength and tensile strain, the optimal content of fly ash is $70 \%$ in this experiment. If the drop of compressive strength of ECC is permit, increasing fly ash content appropriately will help to further improve the toughness and ductility of PVA fiber reinforced cementitious composite.

iii)In this test, when the fly ash content is $65 \%$, the result of the tensile properties is abnormal. So further research on the tensile properties of PVA-ECC under this fly ash content, in order to determine the tensile properties of the material under the content.

iv) in this paper, the results is under the age of 7 days with he direct tensile test, the literature [12] pointed out that in the early age fly ash does not participate in thehydration reaction, but in the later hydration reaction fly ash and the hydration products will produce volcano ash effect, so it needs further study on effect of the tensile properties, the bending properties, compressive and flexural strength, cracking pattern, durability of PVA-ECC with different ages and fly ash content.

\section{REFERENCES}

[1] Li V C.Advances in ECC research [J]. ACI Special Publication on Concrete: Material Science to Applications, 2002: 373-400.

[2] Zhang J,Li V C,Andrzej S N,Wang S. Introducing ductile strip for durability enhancement of concrete slabs[J]. Journal of Materials in Civil Engineering, 2002,14(3) : 253-261.

[3] Li V C, Leung C K Y. Steady state and multiple cracking of short random fiber composites[J]. Journal of Engineering Mechanics, ASCE, 1992, 188 (11) : 2246-2264.

[4] SUN Ming. Research on influence of ECC rheological properties and bending performance with different fiber content and variety(in Chinese, dissertation). Beijing: Beijing Jiaotong University, 2010.

[5] WU Jianhua, PU Xincheng, LIU Fang, et al. High strength high performance concrete with high volume of fly ash[C]//High performance concrete and mineral admixture research and engineering application of the seminars, Zhuhai, 2006:285-293.

[6] Wang Shu Xin. Micromechanics based matrix design for engineered cementitious composites [D]. University of Michigan, 2005 .

[7] Shunxin Wang,Victor C.Li. Engineered Cementitious Composites with High-Volume Fly Ash [J] . ACI Materials Journal, 2007, 104(3):233-241

[8] GONG Chengxu,ZHANG Jun. Tensile performance of high ductile fiber reinforced cementitious composite[J]. Journal of Hydraulic Engineering, 2008, 39(3):361-366(in Chinese)

[9] YANG Yingzi,ZHU Yu,GAO Xiaojian, et al.Experimental study on high-ductile PVA fiber reinforced cement based composite materials with fly ash[J]. Journal of Qingdao Technological University, 2009, 30(4): 51-59 (in Chinese)

[10] PANG Chaoming, LEUNG C K Y,SUN Wei.Preparation and properties of high ductility cementitious composites with high content of fly-ash[J]. Journal of The Chinese Ceramic Society, 2009, 37(12): 2071-2077(in Chinese) 
[11] ZHAO Qingxin, SUN Wei, ZHENG Keren,et al.Influence of fly ash proportion on creep characteristics of high-performance concrete and its mechanism[J].Journal of The Chinese Ceramic Society ,2006, 34(4): 51-54 (in Chinese)
[12] RAO Fangfen. Experimental research on influence of fly ash on flexural properties of ultra high toughness cementitious composite (in Chinese, dissertation). Dalian: Dalian University of Technology, 2008. 